CLINICAL STUDY

\title{
VEGFR 1 expression is related to lymph node metastasis and serum VEGF may be a marker of progression in the follow-up of patients with differentiated thyroid carcinoma
}

\author{
Z Karaca ${ }^{1}$, F Tanriverdi ${ }^{1}$, K Unluhizarci ${ }^{1}$, F Ozturk ${ }^{2}$, S Gokahmetoglu ${ }^{3}$, G Elbuken ${ }^{1}$, I Cakir ${ }^{1}$, \\ $\mathrm{F}$ Bayram ${ }^{1}$ and F Kelestimur ${ }^{1}$ \\ Departments of ${ }^{1}$ Endocrinology, ${ }^{2}$ Pathology and ${ }^{3}$ Microbiology, Erciyes University Medical School, 38039 Kayseri, Turkey \\ (Correspondence should be addressed to K Unluhizarci; Email: kursad@erciyes.edu.tr)
}

\begin{abstract}
Objective: Vascular endothelial growth factor (VEGF) and VEGF receptor 1 (VEGFR1) are known to be related to thyroid tumorigenesis. The aim of the study was to examine the expressions and serum levels of VEGF, VEGFR1, IGF1, and IGF1 receptor (IGF1R) in patients with differentiated thyroid carcinoma (DTC) compared with patients with nodular goiter (NG).

Methods: We examined 39 patients with DTC who had a clinical history of at least 2 years and compared them with 25 patients who had a pathological diagnosis of NG after thyroidectomy. Serum VEGF, VEGFR1, and IGF1 levels were measured in both patient groups. The expressions of VEGF, VEGFR1, IGF1, and IGF1R were analyzed by the immunohistochemical method in the paraffin blocks of patients' thyroidectomy samples of the patients.

Results: The immunostainings scores for VEGF, VEGFR1, IGF1, and IGF1R were found to be higher in patients with DTC than in those with NG. Only VEGFR1 expression was related to lymph node metastasis at the time of surgery. None of the expressions were related to the long-term prognosis of the patients. Serum VEGF was found to be higher in patients with progressive DTC than in patients in clinical remission.

Conclusion: The expressions of VEGF and VEGFR1 were shown to be correlated with the expression of IGF1 and IGF1R. VEGFR1 expression may be an important index for the presence of lymph node metastasis at the time of thyroidectomy. Increased serum levels of VEGF may reflect disease recurrence in DTC.
\end{abstract}

European Journal of Endocrinology $164277-284$

\section{Introduction}

Vascular endothelial growth factor (VEGF), which is secreted from cancer cells, is unique among angiogenic factors as it is mitogenic for vascular endothelial cells. VEGFA, VEGFB, VEGFC, VEGFD (or FIGF), and placental growth factor belong to this family of structurally related molecules. VEGF-A, which is also called VEGF, exists in five different isoforms of $121,145,165,189$, and 206 amino acids (1). VEGF-121 and VEGF-165 isoforms are the principal mediators of tumor angiogenesis (1). These isoforms mainly act through VEGF receptor 2 (VEGFR2). Although VEGF has much more affinity toward VEGFR1, the signaling properties are weaker (2). The role of VEGFR1 in VEGF-mediated angiogenesis is not clear.

It is well known that VEGF expression is increased in differentiated thyroid carcinomas (DTC) compared with normal thyroid gland or benign thyroid lesions (3-6). VEGF mRNA and protein expression were found to be increased in metastatic thyroid tumors when compared with their expression in primary thyroid cancer lesions. Serum VEGF levels were also found to be increased in patients with metastatic thyroid cancer $(3,4,7)$.

The regulation of VEGFC production in thyroid cancer cells is poorly understood. Hypoxia, low pH, inflammatory cytokines such as IL6, growth factors, sex hormones, and chemokines may increase VEGF production (2). A study in the thyroid cancer cell line demonstrated that VEGF production may be increased by insulin-like growth factor 1 (IGF1) via activatory protein 1 (AP1) and hypoxia-inducible factor $1 \alpha$ $($ HIF $1 \alpha)$ (8). Geldanamycin, which is required for the function of kinases such as IGF1 receptor (IGF1R) and Akt, decreased the basal and IGF1-dependent VEGF production by blocking the effect of Hsp90 (8).

The aim of this study is to examine the expressions and serum levels of VEGF, VEGFR1, IGF1, and IGF1R in patients with DTC and their prognostic significance. 


\section{Materials and methods}

Thirty-nine patients with DTC and 25 patients with nodular goiter (NG) as the control group, who were followed up in the Department of Endocrinology, Erciyes University Medical School, were retrospectively studied. Patients with multinodular goiter had total thyroidectomy with confirmed pathological diagnosis. Patients with DTC had a history of thyroid cancer of at least 2 years. The time of DTC diagnosis, data regarding the pathological examination of thyroidectomy specimens, and the treatment histories were reviewed. All patients with thyroid carcinoma had total thyroidectomy and radioactive iodine for remnant thyroid ablation. Prophylactic central lymph node dissection was not a routine procedure in the years patients were operated on. Clinical evalution was carried out in the last 3 months before enrolling the patients into the study. The evaluation consisted of measurement of serum thyroglobulin $(\mathrm{Tg})$, anti- $\mathrm{Tg}$ antibody, and neck ultrasonography (USG) in the last 3 months. The last TSH-stimulated Tg and ${ }^{131}$ I scanning of the patients were recorded. Patients with a negative neck USG, undetectable serum $\mathrm{Tg}$ levels under TSH stimulation, and a negative ${ }^{131}$ I scan were assumed to be in remission whereas patients with increased $\mathrm{Tg}$ or positive neck USG or distant metastasis were assumed to have active disease.

The serum samples for the measurement of VEGF, VEGFR1, and IGF1 were obtained from patients at the time of evaluation. Since the study was retrospectively designed, all patients with NG had had total thyroidectomy and all patients with thyroid cancer had had thyroidectomy and radioactive iodine prior to serum sampling. Pathological examinations of thyroidectomy materials were reviewed and the size of the tumor, multicentricity, the presence of lymph node metastasis, lymphatic, vascular, capsule, and the surrounding tissue invasion were noted.

The study was approved by the ethics committee of Erciyes University and the patients were given informed consent.

\section{Measurement of serum cytokine levels}

Serum VEGF and VEGFR1 levels were measured with the ELISA method with commercially available human VEGF (Invitrogen) and human VEGFR1 BMS268/2 and BMS268/2TEN (Bender MedSystems, Vienna, Austria) kits according to the instructions of the manufacturer. The VEGFR1 measured was soluble VEGFR1. The VEGF levels were recorded as $\mathrm{pg} / \mathrm{ml}$ and the VEGFR 1 levels were recorded as $\mathrm{ng} / \mathrm{ml}$. The serum samples were kept at $-80{ }^{\circ} \mathrm{C}$ in a refrigerator until analysis.

Serum IGF1 levels were measured with a two-sided IRMA, non-extraction active IGF1 IRMA DSL-2800 (Diagnostic System Laboratories, TX, USA). The lower detection limit for IGF1 was $2.06 \mathrm{ng} / \mathrm{ml}$ with intra-assay coefficients of variation (CV) ranging from 3.9 to $7 \%$ and inter-assay $\mathrm{CV}$ values ranging from 3.8 to 7.4 .

\section{Immunohistochemical analysis}

The expressions of VEGF, VEGFR1, IGF1, and IGF1R were examined in the paraffin sections of thyroidectomy material of patients with DTC and NG. Formalin-fixed paraffin wax-embedded sections were cut at $\sim 5 \mu \mathrm{m}$ and floated onto slides. Sections were dewaxed, rehydrated, and placed in antigen retrieval solution and heated in a microwave for $10 \mathrm{~min}$ at a power of $50 \%$. The primary antibody was applied following $3 \% \mathrm{H}_{2} \mathrm{O}_{2}$ application and washing. After the incubation of the primary antibodies $(1 \mathrm{~h}$ in $1 / 150$ dilution for VEGF Ab-7, 1/25 dilution for VEGFR1 Ab1, 1/50 dilution for IGF1 and IGF1R Ab) biotin, streptavidin, and chromogen incubations were carried out respectively. Sections were counterstained with Mayer's hematoxylin.

The antibodies used were polyclonal mouse VEGFAb-7 (Clone VG1) (Lab Vision Corporation, Cheshire, UK), which recognized the 121,165 , and 189 isoforms of VEGF, rabbit polyclonal VEGFR1 Ab1 (Lab Vision Corporation), rabbit polyclonal IGF1 (H-70), sc-9013 (Santa Cruz Biotechnology, Santa Cruz, CA, USA) antibody against the 49-118th amino acids of IGF1 and monoclonal mouse IGF1R antibody (SPM138) (Gene Tex, San Antonio, TX, USA). Angiosarcoma for VEGF and VEGFR 1, renal carcinoma for IGF1, and breast carcinoma for IGF1R were used as positive controls.

\section{Scoring of immunohistochemical analysis}

Scoring of the immunohistochemical analysis was determined by an experienced pathologist (F O) with the previously described methods $(4,9)$. The immunohistochemical analysis was carried out in tumor tissue. The areas were devoid of thyroiditis, nodule, or normal thyroid tissue. The cytoplasm of thyrocytes labeled with the antibodies was evaluated. Examples of scoring are shown in Figs 1 and 2. The VEGF and VEGFR 1 immunostaining scores were calculated by the sum of the percentage of the labeled thyrocytes ( 0 : no staining; 1: $<30 \%$ of thyrocytes; $2: 30-60 \%$ of thyrocytes; 3 : more than $60 \%$ of thyrocytes) and the intensity scores (0: absent; 1: weak; 2: mild; and 3: strong). The IGF1 and IGF1R immunostainings were quantified as grade 0 : no staining; grade 1: mild; grade 2: moderate; grade 3: intense staining.

Blood vessel content (anti-CD31) was examined in three small groups of patients with i) DTC with the highest expression of both VEGF and VEGFR1 $(n=4$ with total scores of 6 for both); ii) DTC with the lowest expression of both VEGF and VEGFR $(n=3)$; and iii) NG $(n=7)$. CD31 expression was calculated by the cells counted in $\times 20$ magnification in three fields. 


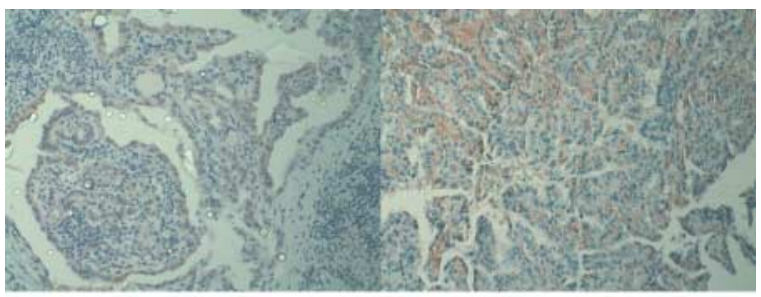

A1

B1
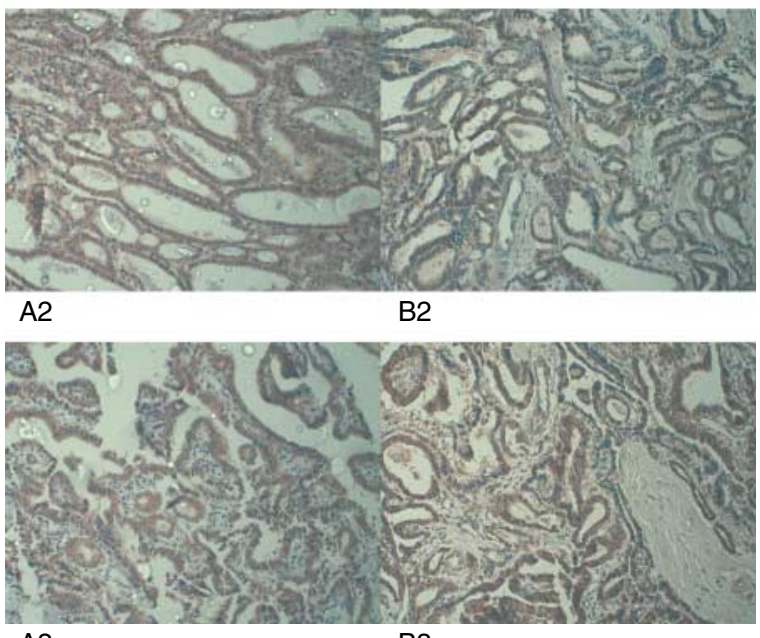

A3

B3

Figure 1 The immunohistochemical staining of thyroid specimens with anti-VEGF and anti-VEGR1 antibodies. A1: weak; A2: mild; A3: strong staining with anti-VEGF antibody. B1: weak; B2: mild; B3: strong staining with anti-VEGFR1 antibody.

\section{Statistical analysis}

All statistical analyses were carried out by Statistical Package for Social Sciences (SPSS for Windows, version 11; Chicago, IL, USA). The continuous data were presented as mean \pm s.D. Normal distribution of the data was tested by the Kolmogorov-Smirnov Z test. Student's $t$-test was used for comparison of the variables that were normally distributed. The immunostaining scores were compared with the Mann-Whitney $U$ test. The correlations of the immunostaining scores were tested with Spearman correlation analysis. An ANCOVA was used for the comparison of age-adjusted values of IGF1 levels. A $P$ value of $<0.05$ was considered as statistically significant.

\section{Results}

Patients with DTC consisted of 35 (89.8\%) women and 4 men $(10.2 \%)$ with an age range between 22 and 78 (mean: $45.62 \pm 11.37$ ). Patients with NG consisted of $23(92 \%)$ women and 2 men $(8 \%)$ with an age range of 26-69 (mean: 46.76 11.28). There were no statistically significant differences between patients with DTC and NG in terms of age and sex distribution.
The investigations were carried out in a mean time of $44 \pm 38$ months after the diagnosis.

The histopathological diagnoses of patients were papillary carcinoma in 30 , follicular variant of papillary carcinoma in 6 , oncocytic variant in 1 , and follicular carcinoma in 2 patients. The pathological features of the patients are summarized in Table 1. The mean serum $\mathrm{TSH}, \mathrm{Tg}$, and anti-Tg antibody levels were $0.68 \pm 1.11 \mathrm{IU} / \mathrm{ml}$ (normal reference range: $0.35-5.06$ ), $0.98 \pm 2.97 \mathrm{ng} / \mathrm{ml}$ (normal reference range: $1.6-60$ ), and $10.6 \pm 8.46 \mathrm{IU} / \mathrm{ml}$ (normal reference range: 10-115) respectively.

No statistically significant difference was detected in the serum VEGF levels between the two groups (mean values: $313.4 \pm 196$ and $288.8 \pm 174 \mathrm{pg} / \mathrm{ml}$ in patients with NG and DTC respectively). The VEGFR1 serum levels were below the detection limit of the assay used in all cases $(<0.16 \mathrm{ng} / \mathrm{ml})$. The serum VEGF levels were found to be positively correlated with the immunostaining scores of VEGF $(P=0.006, r=0.43)$, VEGFR 1 $(P=0.002, r=0.37)$, and IGF1R $(P=0.03, r=0.35)$ in patients with thyroid carcinoma.

Thirty-three $(84.6 \%)$ of the patients were in remission, five $(12.8 \%)$ of them had lymph node metastasis, and one $(2.6 \%)$ had distant metastasis at the time of enrollment. The serum VEGF levels in the patients with local or distant recurrences were found to be higher
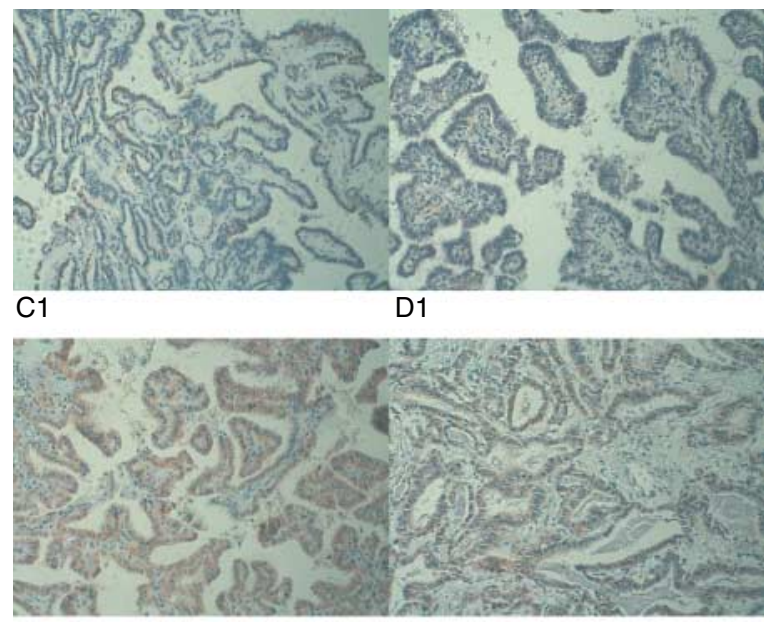

C2

D2

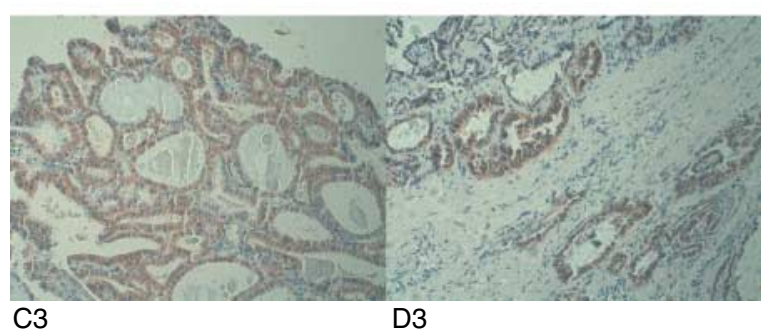

Figure 2 The immunohistochemical staining of thyroid specimens with anti-IGF1 and anti-IGF1R antibodies. C1: mild; C2: moderate; C3: intense staining with anti-IGF1 antibody. D1: mild; D2: moderate; D3: intense staining with anti-IGF1R antibody. 
Table 1 Tumor characteristics of the patients with thyroid carcinoma.

\begin{tabular}{lcc}
\hline Pathological features & Without & With \\
\hline Multicentricity & $33(84.6 \%)$ & $6(15.4 \%)$ \\
Tumor capsule invasion & $31(79.5 \%)$ & $8(20.5 \%)$ \\
Vascular invasion & $37(94.9 \%)$ & $2(5.1 \%)$ \\
Lymphatic invasion & $37(94.9 \%)$ & $2(5.1 \%)$ \\
Thyroid capsule invasion & $38(97.4 \%)$ & $1(2.6 \%)$ \\
Extrathyroidal invasion & $36(92.3 \%)$ & $3(7.7 \%)$ \\
Lymph node metastasis & $28(71.8 \%)$ & $11(28.2 \%)$ \\
Distant metastasis & $39(100 \%)$ & $0(0 \%)$ \\
\hline
\end{tabular}

than in the patients in remission (Table 2). None of the female patients were pregnant or had undergone ovulation induction that could affect the VEGF levels measured at the time of evaluation.

The serum IGF1 levels were similar in patients with DTC and NG. Those patients with local or distant recurrence of DTC tended to have lower serum IGF1 levels, but the age-adjusted ANCOVA did not reveal any statistical significance.

The immunohistochemical staining properties of the patients are summarized in Table 3. The VEGF, VEGFR1, IGF1, and IGF1R immunostaining scores of patients with DTC were found to be significantly higher than those of patients with NG $(P<0.001)$. We found positive correlations between VEGF and IGF1 scores in patients with NG and all immunostaining scores in patients with DTC (Table 4). When the patients with DTC were subgrouped according to the presence of multicentricity, tumor capsule invasion, and lymph node metastasis, all of the immunostaining scores were similar, however, the mean VEGFR1 immunostaining score was found to be higher in patients with lymph node metastasis at first presentation (Table 5).

Although the expression of CD31 was found to be higher in DTC patients with a low expression of VEGF and VEGFR $1(249 \pm 206)$ than in patients with NG $(141 \pm 81)$ it was not statistically significant $(P=0.48)$. CD31 expression was found to be significantly higher in patients with a high expression of VEGF and VEGFR1 $(348 \pm 160)$ than in patients with NG $(P=0.024)$. Finally, the expression of CD31 was found to be higher

Table 2 The serum levels of VEGF, VEGF receptor 1 (VEGFR1), and IGF1 in patients with controlled or progressive disease.

\begin{tabular}{llll}
\hline & $\begin{array}{l}\text { Patients in } \\
\text { remission } \\
(n=33)\end{array}$ & $\begin{array}{l}\text { Patients with } \\
\text { local or distant } \\
\text { recurrence } \\
(n=6)\end{array}$ & P value \\
\hline $\begin{array}{c}\text { Serum VEGF } \\
(\mathrm{pg} / \mathrm{ml})\end{array}$ & $262 \pm 146$ & $436 \pm 247$ & 0.025 \\
$\begin{array}{c}\text { Serum VEGFR1 } \\
(\mathrm{ng} / \mathrm{ml})\end{array}$ & $<0.16$ & $<0.16$ & \\
$\begin{array}{c}\text { Age-adjusted } \\
\text { IGF1 (ng/ml) }\end{array}$ & $234 \pm 62.9$ & $153.71 \pm 60.5$ & 0.063 \\
\hline
\end{tabular}

in DTC patients with a high expression of VEGF and VEGFR1 than in patients with a low expression, but it was not statistically significant $(P=0.42)$. The correlation analysis revealed a positive correlation between CD31 and VEGF expression $(P=0.012, r=0.649)$, but not with CD31 and VEGFR1 expression.

\section{Discussion}

VEGF, which is produced from neoplastic cells, plays an important role in the neovascularization of tumors. The expression of VEGF in thyroid carcinoma has been previously demonstrated by in vitro and in vivo studies $(3,4,6,10)$. Its expression is not only increased in thyroid tumors, but is also thought to have prognostic significance. The risk of recurrence and metastasis was shown to be increased with increased expression of $\operatorname{VEGF}(3,4,11,12)$.

Kilicarslan et al. (13) demonstrated increased immunohistochemical expression of VEGF and microvascular density in 12 recurrent/metastatic and 36 nonrecurrent papillary thyroid cancer cases compared to the normal thyroid gland. They also found increased expression of VEGF in metastatic and recurrent disease. The expression of VEGF is known to be related to the tumor size in DTC in children and young adults, but the finding has not been confirmed by the studies carried out in adults $(11,13,14)$. Although not related to tumor size, the immunohistochemical expression of VEGF is thought to be important in predicting the presence of lymph node and distant metastasis and disease-free survival in DTC (11-13). However, there is also a study that did not reveal the prognostic significance of VEGF expression in patients with thyroid carcinoma (15).

In this study, the expression of VEGF was shown to be higher in patients with DTC than in those with NG, but it was not found to be related to tumor size, capsule invasion, lymph node metastasis, or progression-free survival. Although patients with a history of DTC of at least 2 years were included in this study, the retrospective design of the study may have been a limiting factor for the uniformity of the follow-up period.

The coexpression of VEGF and its receptors was found to be higher in classical papillary thyroid cancer than in the follicular variant and it is related to lymphatic dissemination (16). The effect of VEGF through VEGFR-2 is well known, but that of VEGFR1 is not clear. This study showed that VEGF and VEGFR1 expressions are correlated in thyroid tumor tissue. Although the expression of VEGF was not related to histopathological features of tumors, the VEGFR1 expression was found to be increased in patients with lymph node metastasis at the time of diagnosis. However, neither the expression of VEGF nor of VEGFR1 had any impact on progressionfree survival. 
Table 3 The immunohistochemical staining properties of the patients with differentiated thyroid carcinoma and nodular goiter.

\begin{tabular}{|c|c|c|c|c|}
\hline & \multicolumn{2}{|c|}{ Nodular goiter } & \multicolumn{2}{|c|}{ Thyroid carcinoma } \\
\hline & Mean \pm s.D. & $\begin{array}{c}\text { Median } \\
\text { (minimum-maximum) }\end{array}$ & Mean \pm S.D. & $\begin{array}{c}\text { Median } \\
\text { (minimum-maximum) }\end{array}$ \\
\hline Percentage of labeled thyrocytes with VEGF* & $0.28 \pm 0.54$ & $0(0-2)$ & $1.82 \pm 1.03$ & $2(0-3)$ \\
\hline The intensity of staining with VEGF* & $0.28 \pm 0.54$ & $2(0-3)$ & $1.67 \pm 1.02$ & $1(0-3)$ \\
\hline Total score of VEGF* & $0.56 \pm 1.044$ & $0(0-3)$ & $3.5 \pm 1.91$ & $3(0-6)$ \\
\hline Percentage of labeled thyrocytes with VEGFR1* & $0.76 \pm 0.93$ & $0(0-3)$ & $2.15 \pm 0.89$ & $2(0-3)$ \\
\hline The intensity of staining with VEGFR1* & $0.48 \pm 0.59$ & $2(0-3)$ & $1.87 \pm 0.88$ & $2(0-3)$ \\
\hline Total score of VEGFR $1^{*}$ & $1.24 \pm 1.451$ & $0(0-4)$ & $4.02 \pm 1.64$ & $4(0-6)$ \\
\hline The grade of IGF1 staining* & $0.48 \pm 0.59$ & $0(0-2)$ & $1.33 \pm 0.92$ & $1(0-3)$ \\
\hline The grade of IGF1R staining* & 0 & $0(0-0)$ & $1.03 \pm 0.78$ & $1(0-2)$ \\
\hline
\end{tabular}

${ }^{*} P<0.001$

Although the expression of CD31 was found to be highest in DTC patients with a high expression of VEGF and VEGFR1, lower in DTC patients with a low expression of VEGF and VEGFR1, and lowest in patients with NG, the differences were not found to be statistically significant except between DTC patients with a higher expression of VEGF and VEGFR 1 and patients with NG. Perhaps the small number of patients was the reason for this statistical insignificance, but unfortunately we were only able to study CD31 expression in a limited number of patients who were thought to be the most representative. However, the correlation analysis revealed a positive correlation between $\mathrm{CD} 31$ and VEGF expression $(P=0.012, r=0.649)$, but not with CD31 and VEGFR 1 expression. Further studies with a larger number of cases are warranted.

The principal means of dissemination of papillary cancer is primarily via the lymphatic system (17). VEGF-C and VEGF-D have previously been shown to be related to lymph node metastasis in patients with DTC (18-21). Although lymphangiogenesis is thought to be mediated by VEGFR-3, this study demonstrated a relation between the expression of VEGFR1 and lymph node metastasis in DTC. For the first time, not only VEGFR-3 but also VEGFR1 expression was demonstrated to be related to the lymphatic metastasis of DTC at the time of diagnosis. Therefore, anti-VEGFR agents may have therapeutic potential in such patients.

Studies in thyroid cell lines revealed increased mitogenic effects of TSH in the presence of physiological

Table 4 The correlations of immunohistochemical stainings of patients with nodular goiter and differentiated thyroid carcinoma (DTC).

\begin{tabular}{lcr}
\hline & $\boldsymbol{r}$ & \multicolumn{1}{c}{$\boldsymbol{P}$} \\
\hline $\begin{array}{l}\text { Nodular goiter } \\
\text { VEGF and IGF1 }\end{array}$ & 0.51 & 0.01 \\
DTC & & \\
VEGF and IGF1 & 0.51 & 0.001 \\
VEGF and VEGFR1 & 0.64 & $<0.001$ \\
VEGF and IGF1R & 0.45 & 0.005 \\
VEGFR1 and IGF1 & 0.62 & $<0.001$ \\
VEGFR1 and IGF1R & 0.62 & $<0.001$ \\
\hline
\end{tabular}

concentrations of insulin and IGF1 $(22,23)$. IGF1 and IGF1R are known to be expressed in thyroid cancer $(24,25)$. IGF1R concentration was found to be twice in DTC compared to that of the normal thyroid (26). The clinical importance of IGF1 and IGF1R is not clear although they are known to be expressed in thyroid cancer cells. IGF1 was found to have increased expression in papillary thyroid cancer without a significant effect on clinical progression $(27,28)$. IGF1R expression is not only related to transformation, but also to tumor size and aggressive clinical behavior in adult patients with DTC $(29,30)$. Gydee et al. (9) demonstrated that IGF 1 and its receptor were expressed in tumor tissue in 23 children and adolescents with papillary and 6 with follicular cancer, and the increased expression of IGF1R was related to more aggressive behavior of the tumor. This study revealed higher expressions of IGF1 and IGF1R in patients with DTC than in patients with NG, but we did not find any relation with the histopathological features or progression-free survival of the patients.

Poulaki et al. (8) demonstrated the stimulation of VEGF expression by IGF1 through the phosphatidylinositol-3-kinase pathway by activating HIF1 $\alpha$ and AP1. In addition to higher levels of IGF1 expression in patients with DTC than in patients with NG, the expression of IGF1 was found to be correlated with VEGF expression in both the groups. This study yielded important clinical findings regarding the regulation of VEGF by IGF1 consistent with previous in vitro data. Although the expression of VEGFR1 was found to be correlated with the expression of IGF1 in DTC, the same was not true for patients with NG. Therefore, IGF1 may be one of the inducers of VEGFR 1 in patients with DTC.

The role of circulating VEGF in DTC has not been clarified. The preoperative serum levels of VEGF and VEGFC were found to be higher in patients with papillary thyroid cancer than in those with benign thyroid diseases. VEGFC serum levels were found to decrease after thyroidectomy in patients with papillary thyroid cancer, but were unchanged in patients with benign thyroid diseases. Preoperative VEGF-C has been shown to be an independent risk factor for lymph node 
Table 5 The immunohistochemical stainings of patients with different pathological features in patients with DTC.

\begin{tabular}{|c|c|c|c|c|c|}
\hline & $n$ & VEGF & VEGFR1 & IGF1 & IGF1R \\
\hline \multicolumn{6}{|c|}{ Multicentricity } \\
\hline Without & 33 & $3.7 \pm 2.7$ & $4.3 \pm 1.6$ & $1.7 \pm 1.0$ & $1.0 \pm 0.7$ \\
\hline With & 6 & $3.5 \pm 1.8$ & $4.0 \pm 1.6$ & $1.2 \pm 0.9$ & $1.0 \pm 0.8$ \\
\hline \multicolumn{6}{|c|}{ Tumor capsule invasion } \\
\hline Without & 31 & $4.5 \pm 1.7$ & $4.4 \pm 1.8$ & $1.8 \pm 1.0$ & $1.1 \pm 0.8$ \\
\hline With & 8 & $3.2 \pm 1.9$ & $4.0 \pm 1.6$ & $1.2 \pm 0.9$ & $1.0 \pm 0.8$ \\
\hline \multicolumn{6}{|c|}{ Lymph node metastasis } \\
\hline Without & 28 & $3.8 \pm 2.4$ & $5.2 \pm 1.2^{*}$ & $1.6 \pm 0.8$ & $1.3 \pm 0.8$ \\
\hline With & 11 & $3.4 \pm 1.8$ & $3.6 \pm 1.6 *$ & $1.2 \pm 0.9$ & $0.9 \pm 0.8$ \\
\hline
\end{tabular}

${ }^{*} P=0.006$

metastasis (31). Circulating VEGF has previously been reported to be related to the prognostic factors of papillary thyroid cancer such as tumor size, extrathyroidal extension, lymph node, and distant metastasis (32-34).

This study included only one patient with distant metastasis at the time of evaluation. Circulating VEGF was found to be higher in recurrent or metastatic patients than in patients with controlled disease during follow-up. Therefore, serum VEGF levels may be a marker showing disease progression. However, it is difficult to determine a cut-off level since the mean circulating VEGF levels were not significantly different in the patients with DTC and NG. Prospective studies evaluating serum VEGF levels and prognosis in patients with DTC are warranted.

Studies investigating circulating VEGFR levels are very limited. Hedayati et al. (35) found higher serum VEGF levels in 35 patients with DTC and follicular neoplasia, who were diagnosed with fine needle aspiration biopsy, than in healthy controls, but the VEGFR concentrations were all low in both patient groups. Circulating VEGFR1 levels were found to be below the detection limit of the assay used in both the groups in this study. The VEGFR1 levels are reported to be undetectable in healthy people in the assay procedure.

Although the patients with lymph node metastasis at the time of diagnosis had higher VEGFR 1 expression, it did not seem to have reached measurable levels in the circulation in follow-up. Perhaps the effects may be local. However, since the preoperative VEGFR1 levels were not available, it is difficult to comment on the serum levels in relation to lymph node metastasis at presentation.

Experimental studies have shown significant effects of IGF1 on thyroid growth and goiter $(36,37)$. Studies investigating thyroid disorders in acromegaly have yielded important data regarding the effects of $\mathrm{GH}$ and IGF1 on the thyroid. Besides vascularity, thyroid volume and nodule formation were demonstrated to be increased in patients with acromegaly parallel to disease activity $(38-41)$. The prevalance of thyroid cancer is reported to be increased in patients with acromegaly (41-44).
The relationship between serum IGF1 levels and thyroid disorders has been investigated not only in acromegalic patients but also in healthy subjects. IGF1 levels in thyroid tissue were reported to be increased in patients with multinodular goiter compared to healthy individuals $(45,46)$. Increased serum IGF1 levels were found to be related to the presence of goiter in both sexes and nodule formation in males in 3662 subjects with no history of thyroid disorder (47). In this study, IGF1 serum levels were found to be similar in patients with DTC and NG, but patients with progressive thyroid carcinoma tended to have lower IGF1 levels than the non-progressive group, which was attributed to the older age of the patients with progressive disease. The serum IGF 1 levels seem to be related neither to the presence nor to the prognosis of DTC.

In conclusion, patients with DTC were shown to have higher expressions of VEGF, VEGFR1, IGF1, and IGF1R than patients with NG. Increased immunohistochemical expression of VEGFR 1 may indicate the presence of lymph node metastasis at first diagnosis. Undetectable serum VEGFR 1 levels suggest that VEGFR1 activity is local in DTC. Although circulating VEGF was found to be higher in DTC patients with recurrence than in those who were in remission, further prospective studies with serial measurements are required to determine the sensitivity and specificity of VEGF as a tumor marker in DTC.

\section{Declaration of interest}

The authors declare that there is no conflict of interest that could be perceived as prejudicing the impartiality of the research reported.

\section{Funding}

This study was supported by the Erciyes University Council of Scientific Investigations (project code: TST-08-493).

\section{References}

1 Kerbel RS. Tumor angiogenesis. New England Journal of Medicine 2008358 2039-2049. (doi:10.1056/NEJMra0706596) 
2 Shibuya M \& Claesson-Welsh L. Signal transduction by VEGF receptors in regulation of angiogenesis and lymphangiogenesis. Experimental Cell Research 2006312 549-560. (doi:10.1016/j. yexcr.2005.11.012)

3 Bunone G, Vigneri P, Mariani L, Butó S, Collini P, Pilotti S, Pierotti MA \& Bongarzone I. Expression of angiogenesis stimulators and inhibitors in human thyroid tumors and correlation with clinical pathological features. American Journal of Pathology 1999155 1967-1976.

4 Klein M, Picard E, Vignaud JM, Marie B, Bresler L, Toussaint B, Weryha G, Duprez A \& Leclère J. Vascular endothelial growth factor gene and protein: strong expression in thyroiditis and thyroid carcinoma. Journal of Endocrinology 1999161 41-49. (doi:10.1677/joe.0.1610041)

5 Sato K. Vascular endothelial growth factors and thyroid disorders. Endocrine Journal 200148 635-646. (doi:10.1507/ endocrj.48.635)

6 Soh EY, Duh QY, Sobhi SA, Young DM, Epstein HD, Wong MG, Garcia YK, Min YD, Grossman RF, Siperstein AE \& Clark OH. Vascular endothelial growth factor expression is higher in differentiated thyroid cancer than in normal or benign thyroid. Journal of Clinical Endocrinology and Metabolism $1997 \mathbf{8 2}$ 3741-3747. (doi:10.1210/jc.82.11.3741)

7 Tuttle RM, Fleisher M, Francis GL \& Robbins RJ. Serum vascular endothelial growth factor levels are elevated in metastatic differentiated thyroid cancer but not increased by short-term TSH stimulation. Journal of Clinical Endocrinology and Metabolism 200287 1737-1742. (doi:10.1210/jc.87.4.1737)

8 Poulaki V, Mitsiades CS, McMullan C, Sykoutri D, Fanourakis G, Kotoula V, Tseleni-Balafouta S, Koutras DA \& Mitsiades N. Regulation of vascular endothelial growth factor expression by insulin-like growth factor I in thyroid carcinomas. Journal of Clinical Endocrinology and Metabolism $2003 \mathbf{8 8} 5392-5398$. (doi:10.1210/jc.2003-030389)

9 Gydee H, O'Neill JT, Patel A, Bauer AJ, Tuttle RM \& Francis GL. Differentiated thyroid carcinomas from children and adolescents express IGF-I and the IGF-I receptor (IGF-I-R). Cancers with the most intense IGF-I-R expression may be more aggressive. Pediatric Research 200455 709-715. (doi:10.1203/01.PDR. $0000111282.98401 .93)$

10 Viglietto G, Maglione D, Rambaldi M, Cerutti J, Romano A, Trapasso F, Fedele M, Ippolito P, Chiappetta G, Botti G, Fusco A \& Persico MG. Upregulation of vascular endothelial growth factor (VEGF) and downregulation of placenta growth factor (PlGF) associated with malignancy in human thyroid tumors and cell lines. Oncogene 199511 1569-1579.

11 Klein M, Vignaud JM, Hennequin V, Toussaint B, Bresler L, Plénat F, Leclère J, Duprez A \& Weryha G. Increased expression of the vascular endothelial growth factor is a pejorative prognosis marker in papillary thyroid carcinoma 15 . Journal of Clinical Endocrinology and Metabolism 200186 656-658. (doi:10.1210/ jc.86.2.656)

12 Lennard CM, Patel A, Wilson J, Reinhardt B, Tuman C, Fenton C, Blair E, Francis GL \& Tuttle RM. Intensity of vascular endothelial growth factor expression is associated with increased risk of recurrence and decreased disease-free survival in papillary thyroid cancer 14. Surgery 2001129 552-558. (doi:10.1067/msy.2001. 112592)

13 Kilicarslan AB, Ogus M, Arici C, Pestereli HE, Cakir M \& Karpuzoglu G. Clinical importance of vascular endothelial growth factor (VEGF) for papillary thyroid carcinomas. APMIS: Acta Pathologica, Microbiologica, et Immunologica Scandinavica 2003 111 439-443. (doi:10.1034/j.1600-0463.2003.t01-1-1110209.x)

14 Fenton C, Patel A, Dinauer C, Robie DK, Tuttle RM \& Francis GL. The expression of vascular endothelial growth factor and the type 1 vascular endothelial growth factor receptor correlate with the size of papillary thyroid carcinoma in children and young adults. Thyroid 200010 349-357. (doi:10.1089/thy. 2000.10.349)
15 de la Torre NG, Buley I, Wass JA \& Turner HE. Angiogenesis and lymphangiogenesis in thyroid proliferative lesions: relationship to type and tumour behaviour 10. Endocrine-Related Cancer 200613 931-944. (doi:10.1677/erc.1.01210)

16 Vieira JM, Santos SC, Espadinha C, Correia I, Vag T, Casalou C, Cavaco BM, Catarino AL, Dias S \& Leite V. Expression of vascular endothelial growth factor (VEGF) and its receptors in thyroid carcinomas of follicular origin: a potential autocrine loop. European Journal of Endocrinology 2005153 701-709. (doi:10. 1530/eje.1.02009)

17 Lin JD. Papillary thyroid carcinoma with lymph node metastases 5. Growth Factors 200725 41-49. (doi:10.1080/089771906 01000095)

18 Hung CJ, Ginzinger DG, Zarnegar R, Kanauchi H, Wong MG, Kebebew E, Clark OH \& Duh QY. Expression of vascular endothelial growth factor-C in benign and malignant thyroid tumors 13. Journal of Clinical Endocrinology and Metabolism $2003 \mathbf{8 8}$ 3694-3699. (doi:10.1210/jc.2003-030080)

19 Siironen P, Ristimäki A, Narko K, Nordling S, Louhimo J, Andersson S, Haapiainen R \& Haglund C. VEGF-C and COX-2 expression in papillary thyroid cancer 12. Endocrine-Related Cancer 200613 465-473. (doi:10.1677/erc.1.01114)

20 Tian X, Cong M, Zhou W, Zhu J \& Liu Q. Relationship between protein expression of VEGF-C, MMP-2 and lymph node metastasis in papillary thyroid cancer. Journal of International Medical Research 200836 699-703.

21 Yasuoka H, Nakamura Y, Zuo H, Tang W, Takamura Y, Miyauchi A, Nakamura M, Mori I \& Kakudo K. VEGF-D expression and lymph vessels play an important role for lymph node metastasis in papillary thyroid carcinoma. Modern Pathology 200518 1127-1133. (doi:10.1038/modpathol.3800402)

22 Dumont JE, Lamy F, Roger P \& Maenhaut C. Physiological and pathological regulation of thyroid cell proliferation and differentiation by thyrotropin and other factors. Physiological Reviews 199272 667-697.

23 Milazzo G, La Rosa GL, Catalfamo R, Vigneri R \& Belfiore A. Effect of TSH in human thyroid cells: evidence for both mitogenic and antimitogenic effects. Journal of Cellular Biochemistry 199249 231-238. (doi:10.1002/jcb.240490305)

24 van der Laan BF, Freeman JL \& Asa SL. Expression of growth factors and growth factor receptors in normal and tumorous human thyroid tissues 20. Thyroid $1995 \mathbf{5} 67-73$. (doi:10.1089/ thy.1995.5.67)

25 Vannelli GB, Barni T, Modigliani U, Paulin I, Serio M, Maggi M, Fiorelli G \& Balboni GC. Insulin-like growth factor-I receptors in nonfunctioning thyroid nodules. Journal of Clinical Endocrinology and Metabolism 1990 71 1175-1182. (doi:10.1210/jcem-71-51175)

26 Belfiore A, Pandini G, Vella V, Squatrito S \& Vigneri R. Insulin/IGFI hybrid receptors play a major role in IGF-I signaling in thyroid cancer. Biochimie 199981 403-407. (doi:10.1016/S0300-9084 (99)80088-1)

27 Silva Filho GB, Maciel RM, Takahashi MH, Alberti VN, Castro IV, Saldiva PH, Durazzo MD \& Ferraz AR. Study of immunohistochemical expression of insulin-like growth factor I and proliferating cell nuclear antigen in thyroid gland papillary carcinoma and its metastasis. Head E Neck 199921 723-727. (doi:10.1002/ (SICI)1097-0347(199912)21:8<723::AID-HED7>3.0.CO;2-6)

28 Yashiro T, Ohba Y, Murakami H, Obara T, Tsushima T, Fujimoto Y, Shizume K \& Ito K. Expression of insulin-like growth factor receptors in primary human thyroid neoplasms. Acta Endocrinologica 1989121 112-120. (doi:10.1530/acta.0.1210112)

29 Maiorano E, Ciampolillo A, Viale G, Maisonneuve P, Ambrosi A, Triggiani V, Marra E \& Perlino E. Insulin-like growth factor 1 expression in thyroid tumors. Applied Immunohistochemistry and Molecular Morphology 2000 8 110-119. (doi:10.1097/ 00022744-200006000-00005)

30 Sell C, Dumenil G, Deveaud C, Miura M, Coppola D, DeAngelis T, Rubin R, Efstratiadis A \& Baserga R. Effect of a null mutation of the 
insulin-like growth factor I receptor gene on growth and transformation of mouse embryo fibroblasts. Molecular and Cellular Biology 199414 3604-3612.

$31 \mathrm{Yu}$ XM, Lo CY, Lam AK, Leung P \& Luk JM. Serum vascular endothelial growth factor $\mathrm{C}$ correlates with lymph node metastases and high-risk tumor profiles in papillary thyroid carcinoma. Annals of Surgery 2008247 483-489. (doi:10.1097/ SLA.0b013e31815fa447)

32 Klubo-Gwiezdzinska J, Junik R, Kopczynska E, Juraniec O \& Kardymowicz H. The comparison of serum vascular endothelial growth factor levels between patients with metastatic and non-metastatic thyroid cancer, and patients with nontoxic multinodular goiter. European Journal of Endocrinology 2007157 521-527. (doi:10.1530/EJE-07-0252)

33 Lin SY, Wang YY \& Sheu WH. Preoperative plasma concentrations of vascular endothelial growth factor and matrix metalloproteinase 9 are associated with stage progression in papillary thyroid cancer. Clinical Endocrinology 200358 513-518. (doi:10.1046/j. 1365-2265.2003.01749.x)

$34 \mathrm{Yu}$ XM, Lo CY, Lam AK, Lang BH, Leung P \& Luk JM. The potential clinical relevance of serum vascular endothelial growth factor (VEGF) and VEGF-C in recurrent papillary thyroid carcinoma. Surgery $2008 \mathbf{1 4 4}$ 934-940. (doi:10.1016/j.surg. 2008.07.027)

35 Hedayati M, Kolomecki K, Pasieka Z, Korzeniowska M \& Kuzdak K. Assessment of VEGF and VEGF receptor concentrations in patients with benign and malignant thyroid tumors. Endokrynologia Polska $200556252-258$.

36 Clement S, Refetoff S, Robaye B, Dumont JE \& Schurmans S. Low TSH requirement and goiter in transgenic mice overexpressing IGF-I and IGF-IR receptor in the thyroid gland. Endocrinology 2001 142 5131-5139. (doi:10.1210/en.142.12.5131)

37 Kimura T, Dumont JE, Fusco A \& Golstein J. Insulin and TSH promote growth in size of $\mathrm{PC} \mathrm{Cl3}$ rat thyroid cells, possibly via a pathway different from DNA synthesis: comparison with FRTL-5 cells. European Journal of Endocrinology 1999140 94-103. (doi:10.1530/eje.0.1400094)

38 Bogazzi F, Manetti L, Bartalena L, Gasperi M, Grasso L, Cecconi E, Rago T, Pinchera A \& Martino E. Thyroid vascularity is increased in patients with active acromegaly. Clinical Endocrinology $2002 \mathbf{5 7}$ 65-70. (doi:10.1046/j.1365-2265.2002.01562.x)
39 Cheung NW \& Boyages SC. The thyroid gland in acromegaly: an ultrasonographic study. Clinical Endocrinology 199746 545-549. (doi:10.1046/j.1365-2265.1997.1680985.x)

40 Cheung NW \& Boyages SC. Increased incidence of neoplasia in females with acromegaly. Clinical Endocrinology $1997 \mathbf{4 7}$ 323-327. (doi:10.1046/j.1365-2265.1997.2561053.x)

41 Gasperi M, Martino E, Manetti L, Arosio M, Porretti S, Faglia G, Mariotti S, Colao AM, Lombardi G, Baldelli R, Camanni F, Liuzzi A \& Acromegaly Study Group of the Italian Society of Endocrinology. Prevalence of thyroid diseases in patients with acromegaly: results of an Italian multi-center study. Journal of Endocrinological Investigation 200225 240-245.

42 Balkany C \& Cushing GW. An association between acromegaly and thyroid carcinoma. Thyroid $1995 \mathbf{5}$ 47-50. (doi:10.1089/thy. 1995.5.47)

43 Baris D, Gridley G, Ron E, Weiderpass E, Mellemkjaer L, Ekbom A, Olsen JH, Baron JA \& Fraumeni JF Jr. Acromegaly and cancer risk: a cohort study in Sweden and Denmark. Cancer Causes and Control 200213 395-400. (doi:10.1023/A:1015713732717)

44 Tita P, Ambrosio MR, Scollo C, Carta A, Gangemi P, Bondanelli M, Vigneri R, degli Uberti EC \& Pezzino V. High prevalence of differentiated thyroid carcinoma in acromegaly. Clinical Endocrinology 200563 161-167. (doi:10.1111/j.1365-2265.2005.02316.x)

45 Maiorano E, Ambrosi A, Giorgino R, Fersini M, Pollice L \& Ciampolillo A. Insulin-like growth factor 1 (IGF-1) in multinodular goiters: a possible pathogenetic factor. Pathology, Research and Practice $19941901012-1016$.

46 Minuto F, Barreca A, Del Monte P, Cariola G, Torre GC \& Giordano G. Immunoreactive insulin-like growth factor I (IGF-I) and IGF-I-binding protein content in human thyroid tissue. Journal of Clinical Endocrinology and Metabolism $1989 \mathbf{6 8}$ 621-626. (doi:10.1210/jcem-68-3-621)

47 Volzke H, Friedrich N, Schipf S, Haring R, Ludemann J, Nauck M, Dorr M, Brabant G \& Wallaschofski H. Association between serum insulin-like growth factor-I levels and thyroid disorders in a population-based study. Journal of Clinical Endocrinology and Metabolism 200792 4039-4045. (doi:10.1210/jc.2007-0816)

Received 5 November 2010

Accepted 19 November 2010 